\title{
Approaches to radar reflectivity bias correction to improve rainfall estimation in Korea
}

\author{
Cheol-Hwan You ${ }^{1}$, Mi-Young Kang ${ }^{2}$, Dong-In Lee ${ }^{1,2}$, and Jung-Tae Lee ${ }^{2}$ \\ ${ }^{1}$ Atmospheric Environmental Research Institute, Pukyong National University, Busan, South Korea \\ ${ }^{2}$ Department of Environmental Atmospheric Sciences, Pukyong National University, Busan, South Korea \\ Correspondence to: Dong-In Lee (leedi@pknu.ac.kr)
}

Received: 13 December 2015 - Published in Atmos. Meas. Tech. Discuss.: 18 January 2016

Revised: 6 April 2016 - Accepted: 22 April 2016 - Published: 4 May 2016

\begin{abstract}
Three methods for determining the reflectivity bias of single polarization radar using dual polarization radar reflectivity and disdrometer data (i.e., the equidistance line, overlapping area, and disdrometer methods) are proposed and evaluated for two low-pressure rainfall events that occurred over the Korean Peninsula on 25 August 2014 and 8 September 2012. Single polarization radar reflectivity was underestimated by more than 12 and $7 \mathrm{~dB}$ in the two rain events, respectively. All methods improved the accuracy of rainfall estimation, except for one case where drop size distributions were not observed, as the precipitation system did not pass through the disdrometer location. The use of these bias correction methods reduced the RMSE by as much as $50 \%$. Overall, the most accurate rainfall estimates were obtained using the overlapping area method to correct radar reflectivity.
\end{abstract}

\section{Introduction}

Radar is a useful remote sensing instrument for measuring rainfall amount due to its relatively high resolution in both space and time. Areal rainfall rate must be derived from radar reflectivity, not measured directly. This estimation of radar rainfall is based on the relationship between reflectivity $(Z)$ and rainfall rate $(R)$, known as the $Z-R$ relation $(R(Z))$. Experimentally measured drop size distributions (DSDs) have been used extensively to obtain both radar reflectivity and rainfall rate (Compos and Zawadzki, 2000; Jang et al., 2004; You et al., 2004). There is no unique $R(Z)$, since DSDs can be varied storm to storm and even within a single storm (Battan, 1973; You et al., 2010).
However, radar rainfall estimation is complicated by a number of uncertainties including hardware calibration, partial beam filling, rain attenuation, bright band, and nonweather echoes (Wilson and Brandes, 1979; Austin, 1987). The correction of bias in $Z$ caused by hardware calibration error is difficult to achieve using single polarimetric radar (SPOL) alone. Polarimetric radar (DPOL) provides a new method for the absolute calibration of reflectivity, which has been a longstanding problem with single polarization radar data. The method is based on the assumptions that $Z$, differential reflectivity $\left(Z_{\mathrm{DR}}\right)$, and specific differential phase $\left(K_{\mathrm{DP}}\right)$ are independent of each other and that $Z$ can be estimated from $Z_{\mathrm{DR}}$ and $K_{\mathrm{DP}}$, which are insensitive to radar miscalibration (Gorgucci et al., 1992, 1999; Goddard et al., 1994; Scarchilli et al., 1996; Vivekanandan et al., 1999).

The Korea Meteorological Administration (KMA) is in the process of replacing Doppler radars with S-band DPOLs (to be completed by 2019), and the Ministry of Land, Infrastructure, and Transport (MoLIT) has installed four S-band DPOLs for operational use since 2009. Until the DPOL installation is complete, it is necessary to use a combination of SPOLs and DPOLs to produce rainfall mosaics covering the whole Korean Peninsula. To obtain more accurate mosaicked radar rainfall, SPOL reflectivity should be corrected using the reflectivity of DPOLs and other instruments such as the disdrometer. Accurate SPOL reflectivity is also required for climatological analysis using radar rainfall.

This paper discusses three methods for reducing errors in SPOL reflectivity using DPOL and DSD measurements. In Sect. 2, the data set used for the analysis is introduced, and three approaches to correcting SPOL reflectivity are described, along with methods for bias correction of DPOL re- 


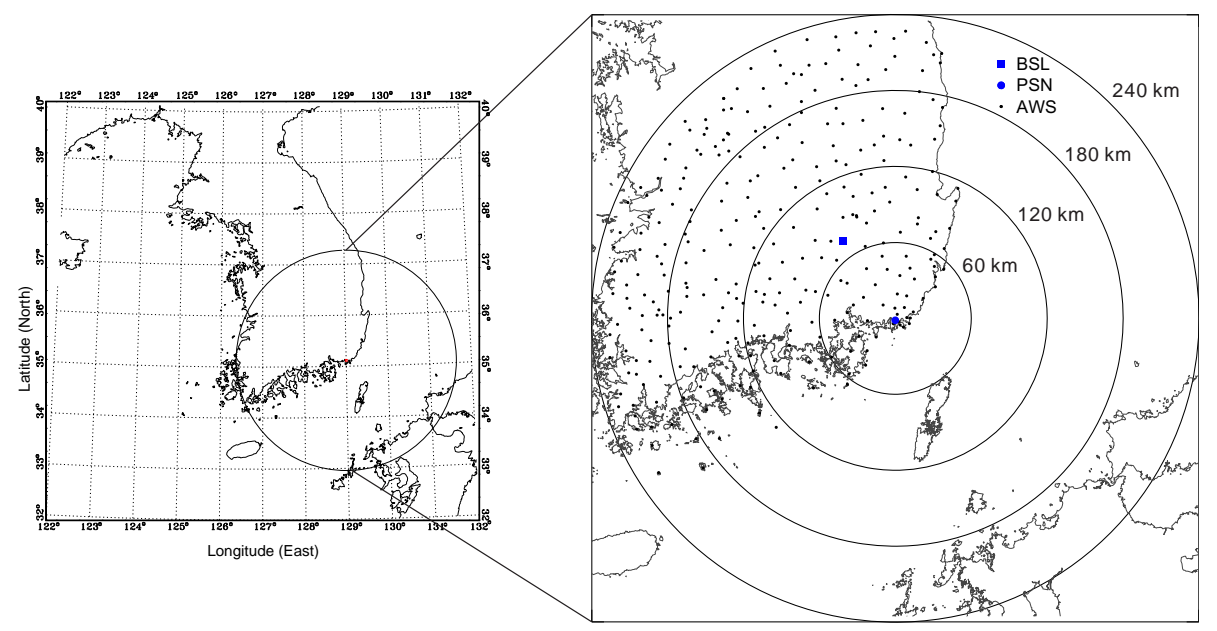

Figure 1. Location of the Bislsan radar (solid rectangle), the PARSIVEL disdrometer and Gudeok radar (solid circle), and rain gages (black dots) distributed within $240 \mathrm{~km}$ of radar coverage. Circles indicate distance from the Gudeok radar and are drawn at intervals of $60 \mathrm{~km}$.

flectivity and $Z_{\mathrm{DR}}$ and for validation. In Sect. 3, the results obtained using the three correction methods are compared with gage measurements. Finally, we summarize the results and provide conclusions in Sect. 4.

\section{Data}

Rainfall data from rain gages operated by the KMA were used to evaluate the accuracy of radar rainfall. Rain gages located between 5 and $134 \mathrm{~km}$ from the radar were included in the analysis. Figure 1 shows the location of all instruments used in this study. The PARSIVEL (PARticle SIze VELocity) disdrometer was installed $\sim 9 \mathrm{~km}$ from PSN (Pusan radar). PARSIVEL is a laser-optic system that measures 32 channels from 0.062 to $24.5 \mathrm{~mm}$ (for detailed specifications, see Loffler-Mang and Joss, 2000).

Data observed from PARSIVEL were regarded as unreliable and removed from the analysis in the case that any of the following conditions were met: $1 \mathrm{~min}$ rain rate was less than $0.1 \mathrm{~mm} \mathrm{~h}^{-1}$; total number concentration from all channels was less than 10; drop numbers were recorded only in the lower 10 channels $(1.187 \mathrm{~mm}$ for PARSIVEL); drop numbers were recorded only in the lower 5 channels $(0.562 \mathrm{~mm}$ for PARSIVEL) (You and Lee, 2015).

Radar data were recorded at PSN (Pusan radar), which is located at the coastal line, and BSL (Bislsan radar), which is located $76.9 \mathrm{~km}$ away from PSN (Fig. 1); these radars were installed and are operated by KMA and MoLIT, respectively. The transmitted peak power of BSL is $750 \mathrm{~kW}$, the beam width is $0.95^{\circ}$, the frequency is $2.791 \mathrm{GHz}$, and the antenna is $1085 \mathrm{~m}$ above sea level (ma.s.l.). The polarimetric variables are estimated with a gate size of $0.125 \mathrm{~km}$. The scan strategy consists of six elevation angles with a 2.5 min update interval. The transmitted peak power of PSN is $800 \mathrm{~kW}$, the beam width is $1.0^{\circ}$, the frequency is $2.712 \mathrm{GHz}$, and the an-
Table 1. Rainfall events used for the analysis.

\begin{tabular}{lll}
\hline Date & Source & Period of analysis \\
\hline 8 September 2012 & Low pressure & 00:00 to 06:00 LST \\
25 August 2014 & Low pressure & 09:00 to 16:00 LST \\
\hline
\end{tabular}

tenna is $547 \mathrm{~m}$ a.s.l. The reflectivity is estimated with a gate size of $0.25 \mathrm{~km}$. The PSN scan strategy consists of 13 elevation angles with a 10 min update interval. Radar variables at an elevation angle of $0.5(1.8)^{\circ}$ were extracted from the BSL (PSN) data every $10 \mathrm{~min}$, to match the time interval for this study. Non-meteorological targets were removed from the PSN data using the texture and vertical gradient of reflectivity, as proposed by Zhang et al. (2004). Polarimetric variables were subjected to quality control using a threshold of $15^{\circ}$ for the standard deviation of the differential phase shift (You et al., 2014).

The quality controlled $Z_{\mathrm{H}}, Z_{\mathrm{DR}}$, and $K_{\mathrm{DP}}$ measured from BSL were used to calibrate $Z_{\mathrm{DR}}$ and $Z_{\mathrm{H}}$ of BSL. The $Z_{\mathrm{H}}$ measured from PSN was then corrected by using calibrated $Z_{\mathrm{H}}$ of BSL using self-consistency method and $Z_{\mathrm{H}}$ measured by PARSIVEL. The gage rainfall data were used to assess the performance of three $Z_{\mathrm{H}}$ bias correction methods for PSN which is SPOL.

The accuracy of rainfall estimation using corrected reflectivity was evaluated to measure the effectiveness of each method for calculating the difference reflectivity between PSN and BSL (PARSIVEL). Two rainfall events were used, occurring on 25 August 2014 and 8 September 2012 (Table 1). The August and September events were caused by low-pressure systems over the Korean Peninsula, respectively.

Figure 2 shows the time series of $Z_{\mathrm{H}}$ observed from BSL radar on 8 September 2012 and 25 August 2014. The pre- 
(a)

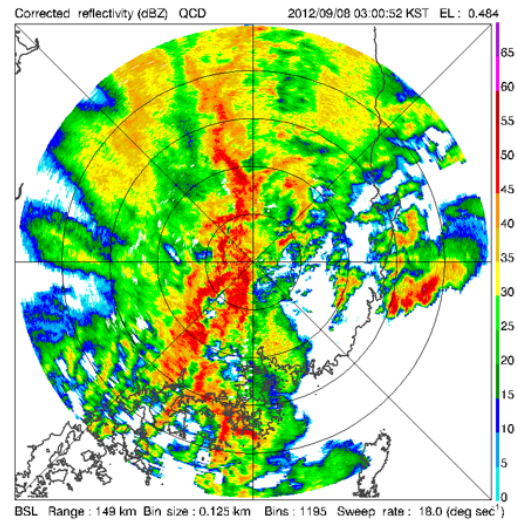

(d)

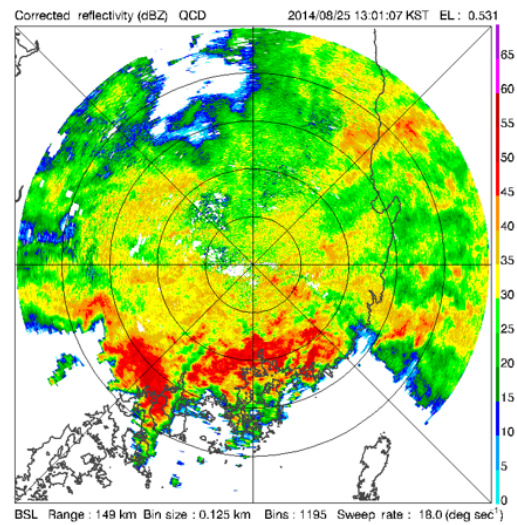

(b)

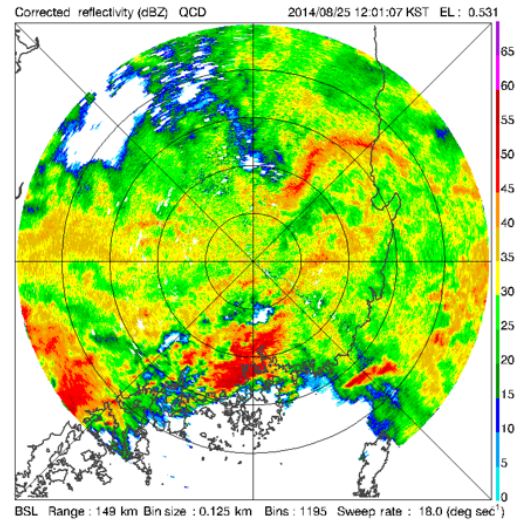

(e)

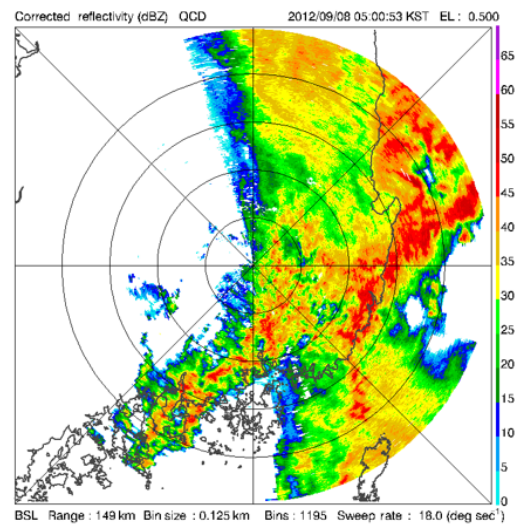

(c)

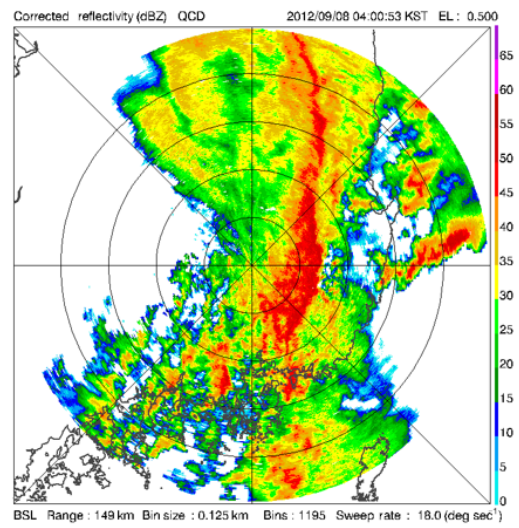

(f)

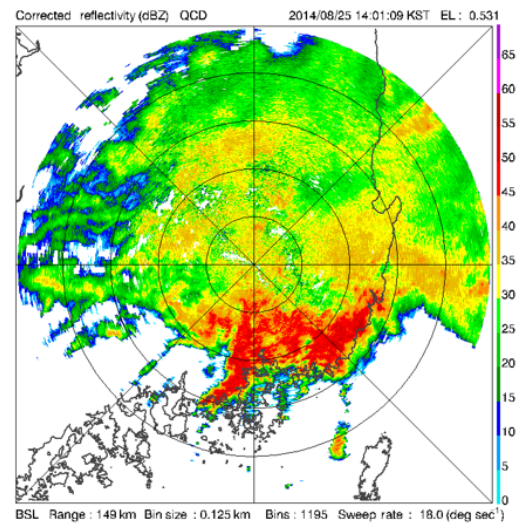

Figure 2. Time series of horizontal reflectivity $\left(Z_{\mathrm{H}}\right)$ at 0.5 elevation angle observed from BSL (a) 04:00 LT, (c) 05:00 LT, and (e) 06:00 LT on 8 September 2012 and (b) 12:00 LT, (d) 13:00 LT, and (f) 14:00 LT on 25 August 2014.

cipitation within radar coverage on 8 September 2012 was caused by low pressure with the front located at northern part of Korea. The core of the precipitation systems elongated from south to north and moved eastward. The maximum reflectivity of the core was more than $45 \mathrm{dBZ}$ and caused rainfall in the western part of radar coverage at 03:00 LST (Fig. 2a), became more organized at the eastern part of radar coverage at 04:00 LST (Fig. 2c), and moved eastward and were located around the coast at 05:00 LST (Fig. 2e) on 8 September 2012. The precipitation system on 25 August 2014 was caused by the low pressure located in the southern part of Korea. The two areas of strong rainfall within the radar coverage were located in the southwestern part of the radar coverage with distance between 120 and $150 \mathrm{~km}$ and in the southern part of the radar coverage with distance between 30 and $90 \mathrm{~km}$ at 12:00 LST on 25 August 2014 (Fig. 2b). The two convective cells moved eastward, their strength intensified, and the area of rainfall was wider at 13:00 LST (Fig. 2d). The two systems moved eastward continuously and merged together at 14:00 LST (Fig. 2f).
Figure 3 shows the time series of hourly rainfall and daily accumulation measured by a gage which recorded highest daily rainfall within radar coverage on 8 September 2012 and 25 August 2014. The highest daily accumulated rainfall was recorded from North Changwon (ID 255) and Geumjeong (ID 939) on each day, respectively. The daily accumulation of ID 255 was $150 \mathrm{~mm}$, the maximum hourly rainfall was around $40 \mathrm{~mm}$, and the duration of the rainfall was $7 \mathrm{~h}$ (Fig. 3a). The daily accumulation of ID 939 was around $270 \mathrm{~mm}$ and the maximum hourly rainfall was more than $100 \mathrm{~mm} \mathrm{~h}^{-1}$. The rainfall amount for $3 \mathrm{~h}(10: 00,14: 00$, and 15:00 LST) mainly contributed to the total rainfall accumulation on 25 August 2014 (Fig. 3b).

\section{Methodology}

\section{1 $Z$ and $Z_{\mathrm{DR}}$ bias correction for BSL}

Before calculating reflectivity bias for PSN using BSL, $Z_{\mathrm{H}}$ and $Z_{\mathrm{DR}}$ must be corrected for bias. $Z_{\mathrm{DR}}$ bias correction is important for the absolute calibration of the radar using a self-consistency method. Gorgucci et al. (1999) proposed 

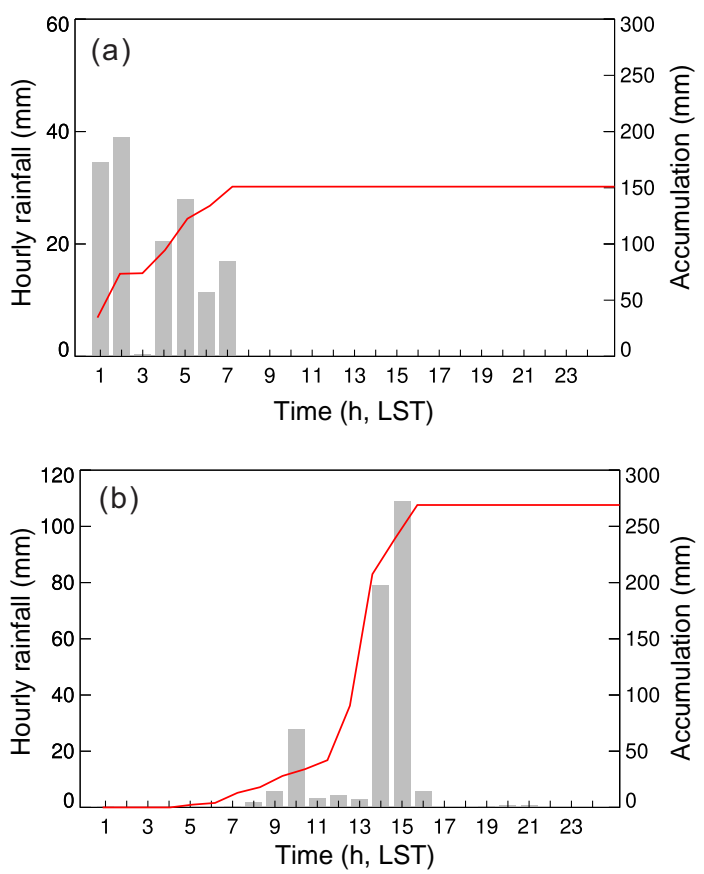

Figure 3. Time series of $1 \mathrm{~h}$ rainfall (bar) and daily accumulated (red line) measured from a gage which recorded highest daily rainfall within radar coverage at (a) North Changwon (ID 255) on 8 September 2012 and (b) Geumjeong (ID 939) on 25 August 2014.

using a vertical pointing scan of light rain to take advantage of the nearly spherical shape of the raindrops as seen from below. Ryzhkov et al. (2005) used the elevation angle dependency of $Z_{\mathrm{DR}}$ as an alternative technique and concluded that the high variability of $Z_{\mathrm{DR}}$ in rainfall prohibited the method from achieving the required absolute calibration accuracy of $0.2 \mathrm{~dB}$. They instead proposed a method that utilizes the structural characteristics of the melting layer in stratiform clouds and the dry aggregated snow present above the melting layer. $Z_{\mathrm{DR}}$ measurements from dry aggregated snow above the melting layer resulted in a mean S-band value of $0.2 \mathrm{~dB}$ and an accuracy of $0.1-0.2 \mathrm{~dB}$. Trabal et al. (2009) evaluated two methods using the intrinsic properties of dry aggregated snow present above the melting layer and light rain measurements close to the ground and found that a $Z_{\mathrm{DR}}$ calibration accuracy of $0.2 \mathrm{~dB}$ or better was achieved using either method.

Vertical pointing data were not available in the present case, and the scan strategy, with six elevation angles, was unable to detect the melting layer. Therefore, in this study, light rain measurements close to the ground were used to calibrate $Z_{\mathrm{DR}}$. Light rain was defined using a threshold of $20 \mathrm{dBZ} \leq Z \leq 28 \mathrm{dBZ}$, as proposed by Marks et al. (2011). The assumption of $Z_{\mathrm{DR}}$ is close to 0 in the case of the small raindrop-like drizzle chosen for this study. The $Z_{\mathrm{DR}}$ values observed from BSL with reflectivity in the range of 20 to
$28 \mathrm{dBZ}$ for a given time period were averaged. Then the averaged $Z_{\mathrm{DR}}$ was taken as a $Z_{\mathrm{DR}}$ bias.

The $Z_{\mathrm{H}}$ bias was calculated by a self-consistency method using a nine-gate moving average of bias-corrected $Z_{\mathrm{DR}}$ in the range of 0.2 to $3.0 \mathrm{~dB}$ to improve the accuracy. This method depends on the notion that $Z_{\mathrm{H}}, Z_{\mathrm{DR}}$, and $K_{\mathrm{DP}}$ are independent in rain and that $Z_{\mathrm{H}}$ can be estimated from $Z_{\mathrm{DR}}$ and $K_{\mathrm{DP}}$. The difference between the computed and observed values of $Z_{\mathrm{H}}$ is referred to as the $Z$ bias. Following the method of Ryzhkov et al. (2005), the entire spatial and temporal domain was divided into $1 \mathrm{~dB}$ intervals of $Z_{\mathrm{H}}$ between $Z_{\min }(30 \mathrm{dBZ})$ and $Z_{\max }(50 \mathrm{dBZ})$, and the $K_{\mathrm{DP}}\left(Z_{\mathrm{H}}\right)$ and $Z_{\mathrm{DR}}\left(Z_{\mathrm{H}}\right)$ within each interval were calculated. The $Z_{\mathrm{H}}$ bias is then determined by matching the integrals as follows:

$$
\begin{aligned}
& I_{1}=\sum_{Z_{\min }}^{Z_{\max }} K_{\mathrm{DP}}(Z) n(Z) \Delta Z, \\
& I_{2}=\sum_{Z_{\min }}^{Z_{\max }} 10^{0.1 Z_{m}} f\left(Z_{\mathrm{DR}}\right) n(Z) \Delta Z,
\end{aligned}
$$

The function of $f\left(Z_{\mathrm{DR}}\right)$ in Eq. (2) can be well approximated by a fourth-order polynomial fit for certain range of $Z_{\mathrm{DR}}$ (Gourley et al., 2009) like Eq. (3).

$f\left(Z_{\mathrm{DR}}\right)=10^{-5}\left(a_{0}+a_{1} Z_{\mathrm{DR}}+a_{2} Z_{\mathrm{DR}}^{2}+a_{3} Z_{\mathrm{DR}}^{3}\right)$.

The estimated $Z_{\mathrm{H}}$ bias is determined from Vivekanandan et al. (2003) by

$Z_{\mathrm{H}} \operatorname{bias}(\mathrm{dB})=10 \log \left(\frac{I_{2}}{I_{1}}\right)$,

If the radar is well calibrated, $Z_{\mathrm{H}}$ bias should be equal to 0 . The coefficients of $f\left(Z_{\mathrm{DR}}\right)$ were calculated by $T$-matrix scattering method using long period DSD data and are 4.26, $-4.67,2.67$, and -0.54 , respectively.

\subsection{Equidistance line method}

To calculate the reflectivity bias of PSN, which is a single polarization radar, three approaches were used: the equidistance line method, the overlapping area method, and the disdrometer method. The first approach is to compare the reflectivities along the line that is equidistant between the two radars. To determine this line for the two radars, the effective radius was set to $100 \mathrm{~km}$, and the distance between the two radars and the azimuthal angle pointing from BSL to PSN were calculated using their latitude and longitude values. The start and end azimuthal angles for comparison of reflectivity were then calculated as follows:

$$
\begin{aligned}
& \mathrm{AZ}_{\mathrm{st}}=\beta-a \cos (0.5 \times d r / r c), \\
& \mathrm{AZ}_{\mathrm{end}}=\beta-a \cos (0.5 \times d r / r c)+2 \times a \cos (0.5 \times d r / r c),
\end{aligned}
$$

where $\mathrm{AZ}_{\mathrm{st}}$ and $\mathrm{AZ}_{\text {end }}$ are the start and end azimuthal angles for the comparison, respectively; $\beta$ is an azimuthal angle, 
which is the angle between north and the bearing from BSL points to PSN and $r c$ and $d r$ are the effective radius and distance from BSL to PSN, respectively. The distance between the two radars is $76.9 \mathrm{~km}$, and the start and end azimuthal angles of BSL (PSN) are $79(35)$ and $213(261)^{\circ}$, respectively (Fig. 4).

To compare the reflectivity observed of targets at the almost same height from both radars, the beam height was calculated assuming a standard atmospheric beam propagation (Rinehart, 2010), as follows:

$H=\sqrt{r^{2}+\left(R^{\prime}+H_{0}\right)^{2}+2 r\left(R^{\prime}+H_{0}\right) \sin \varphi}-R^{\prime}$,

where $r$ is the slant range from the radar, $\varphi$ is the elevation angle of the radar beam, $H_{0}$ is the height of the radar antenna above sea level, and $R^{\prime}=(4 / 3) R$, where $R$ is the Earth's radius $(6371 \mathrm{~km})$. The radar antenna heights of PSN and BSL are 547 and $1085 \mathrm{~m}$, respectively. Figure 5 shows the beam height of PSN with blue solid line and BSL at the equidistance line (blue dashed line as shown in Fig. 4). EL1 to EL6 show the elevation angles from smallest to largest. The smallest difference in beam height between the two radars is $149 \mathrm{~m}$, which was obtained using the fourth elevation angle of PSN and the third elevation angle of BSL. Therefore, the reflectivity bias of PSN was calculated by averaging the difference of reflectivity along with the equidistance line observed from the fourth elevation angle of PSN and the third one of BSL.

\subsection{Overlapping area method}

In the second approach, the overlapping area for the two radars was calculated by matching the coordinates. The polar coordinate of two radars was converted to a Cartesian coordinate with a spatial resolution of $1 \mathrm{~km}$. The overlapping area was then determined by considering the distances between the two radars in the east-west and north-south directions. Figure 6 shows a schematic diagram of the overlapping area for the two radars. The distance between the two radars in east-west and north-south direction is 42 and $64 \mathrm{~km}$, respectively. The reflectivity observed from both radars at the pixels designated at the overlapping area as shown by a blue rectangle in the right panel of Fig. 6, was compared to calculate the $Z_{\mathrm{H}}$ bias of PSN. The extracted domain of PSN and BSL for the comparison is $158 \times 136 \mathrm{~km}$.

\subsection{Disdrometer method}

The third and final approach is to use DSD observations from the PARSIVEL disdrometer. The reflectivity was calculated from the DSD at $1 \mathrm{~min}$ resolution and averaged over $10 \mathrm{~min}$ to match the radar time resolution. Figure 7 shows a schematic of the procedure used to match the radar and PARSIVEL data. The PARSIVEL disdrometer is located $\sim 9 \mathrm{~km}$ from the radar, at an azimuthal angle of $87^{\circ}$. The radar reflectivity was averaged over a domain of 13 gates $\times 3^{\circ}$ in

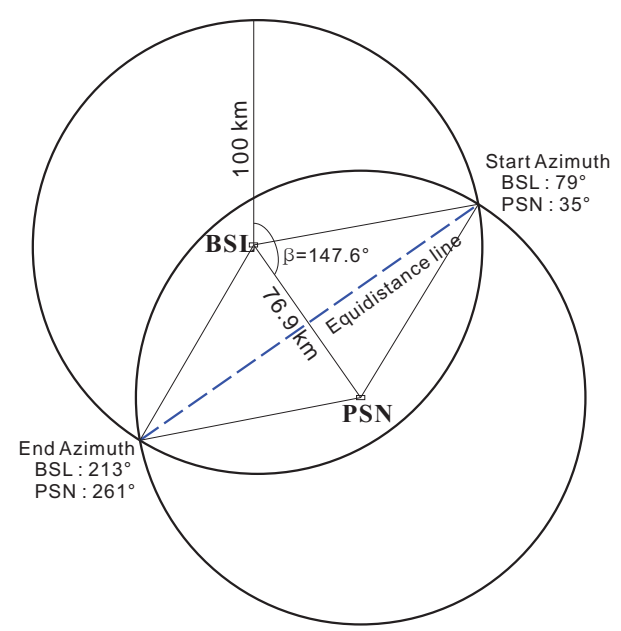

Figure 4. Schematic diagram showing the method used to calculate the line of equidistance between two radars. The effective radius was set to $100 \mathrm{~km}$ and the distance between radars is $76.9 \mathrm{~km}$. The azimuthal angle from BSL to PSN is $147.6^{\circ}$. The start and end azimuthal angles are $79(35)$ and $213(261)^{\circ}$ for BSL (PSN), respectively. The blue dashed line shows the equidistance line.

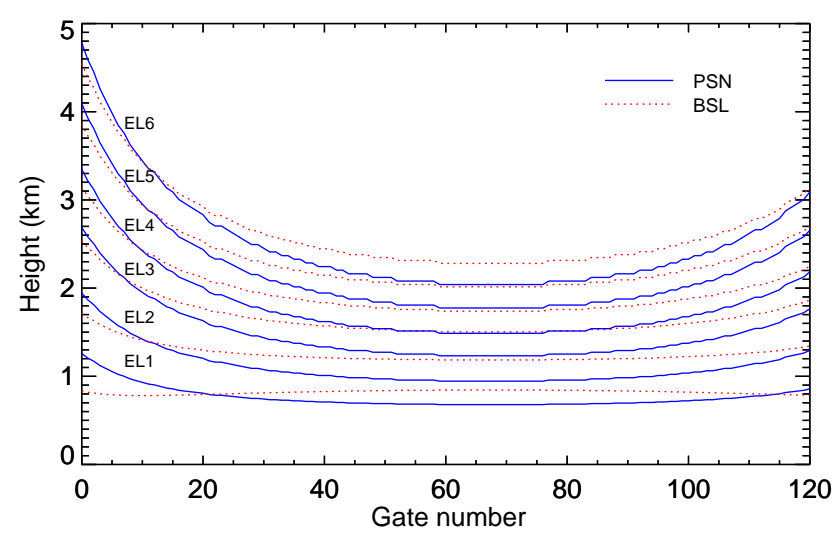

Figure 5. Beam height of PSN (blue solid lines) and BSL (red dotted lines) at the equidistance line. EL1 to EL6 show the first, second, third, fourth, fifth, and sixth elevation angles, respectively.

azimuth, centered at the PARSIVEL location. The reflectivity observed by BSL or PARSIVEL subtracted from that observed by PSN was taken as a $Z_{\mathrm{H}}$ bias and it will be applied to all pixels of PSN coverage.

\subsection{Validation}

The normalized error (NE), root-mean-square error (RMSE), and correlation coefficient (CC) between rainfall estimates and measurements from 121 gages were calculated to measure the performance of each bias correction method. The rain gages were $0.5 \mathrm{~mm}$ tipping-bucket type. Time resolution of gages is $1 \mathrm{~min}$ and data quality control was done by KMA. 

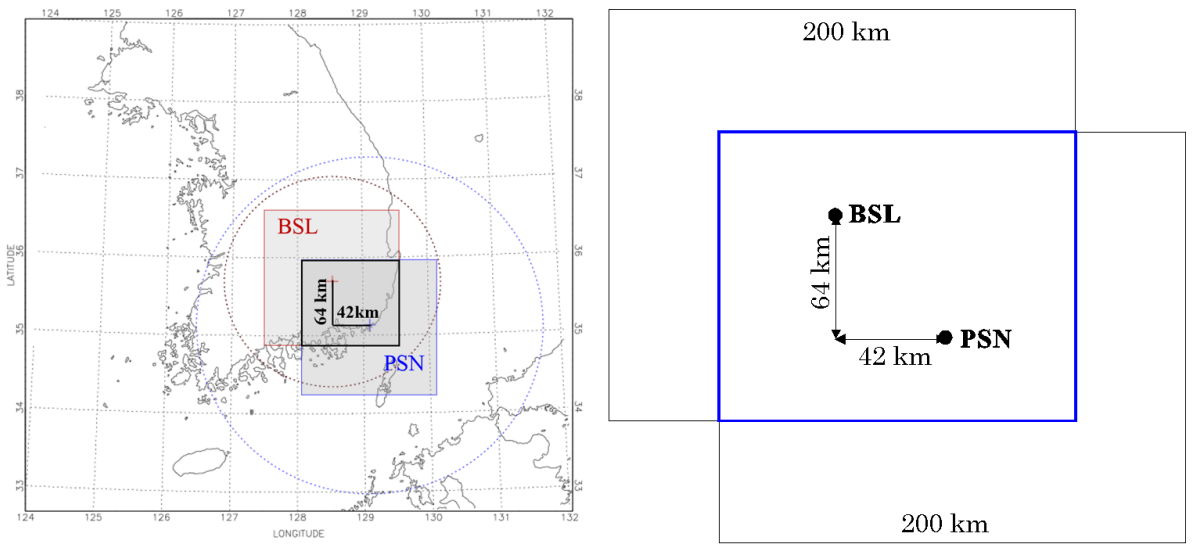

Figure 6. Schematic diagram of the overlapping area for BSL and PSN. The east-west and north-south distances between the two radars are 42 and $64 \mathrm{~km}$, respectively. The red (blue) dotted circle shows the maximum range of BSL (PSN) and gray shaded area show $200 \mathrm{~km}$ by $200 \mathrm{~km}$ extracted from each radar coverage in the left panel.

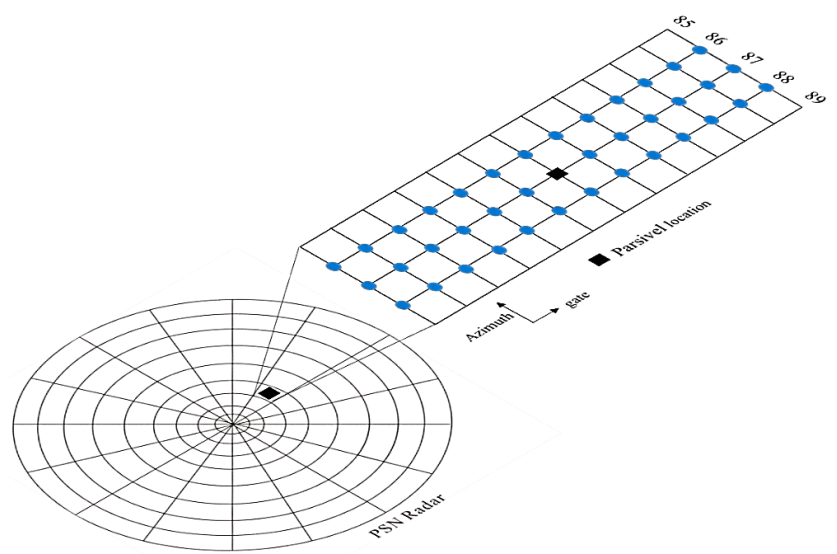

Figure 7. Schematic diagram showing matching of the radar gate and the PARSIVEL disdrometer. PARSIVEL is located $\sim 9 \mathrm{~km}$ from the radar, at an azimuthal angle of $87^{\circ}$. The radar reflectivity was averaged over a $3 \mathrm{~km} \times 3^{\circ}$ domain centered at the PARSIVEL location.

These quantities are defined as follows:

$\mathrm{NE}=\frac{\frac{1}{N} \sum_{i=1}^{N}\left|R_{\mathrm{R}, i}-R_{\mathrm{G}, i}\right|}{\overline{R_{\mathrm{G}}}}$,

$\operatorname{RMSE}=\left[\frac{1}{N} \sum_{i=1}^{N}\left(R_{\mathrm{R}, i}-R_{\mathrm{G}, i}\right)^{2}\right]^{1 / 2}$,

$\mathrm{CC}=\frac{\sum_{i=1}^{N}\left(R_{\mathrm{R}, i}-\overline{R_{\mathrm{R}}}\right)\left(R_{\mathrm{G}, i}-\overline{R_{\mathrm{G}}}\right)}{\left[\sum_{i=1}^{N}\left(R_{\mathrm{R}, i}-\overline{R_{\mathrm{R}}}\right)^{2}\right]^{1 / 2}\left[\sum_{i=1}^{N}\left(R_{\mathrm{G}, i}-\overline{R_{\mathrm{G}}}\right)^{2}\right]^{1 / 2}}$, where $N$ is the number of radar rainfall $\left(R_{\mathrm{R}}\right)$ and gage rainfall $\left(R_{\mathrm{G}}\right)$ pairs, and $\overline{R_{\mathrm{R}}}$ and $\overline{R_{\mathrm{G}}}$ are the average hourly rain rates from radar and gages, respectively. These quantities were calculated using total accumulated rainfall amounts for analyzed time period from radar and gage measurements at each point. The radar rainfall value at each point was obtained by averaging rainfall over a small area $\left(1 \mathrm{~km} \times 1^{\circ}\right)$ centered on the corresponding rain gage. The radar rainfall was calculated using the relation $Z=200 R^{1.6}$ and $Z=300 R^{1.4}$

\section{Results}

\subsection{Equidistance line method}

Before estimating radar rainfall rates, reflectivity biases were calculated using each of the three methods. Figure 8 shows time series of the average reflectivity difference between PSN and BSL at the equidistance line and the number of samples used in each calculation, on 25 August 2014. The average difference over the entire time period was $-7.85 \mathrm{~dB}$, and the largest difference was $-12.46 \mathrm{~dB}$. It means that the reflectivity observed by PSN was underestimated comparing with BSL. The number of samples used for each calculation was determined using a beam height difference threshold of $0.1 \mathrm{~km}$. The number of samples was generally above 60 , but it was smaller than 60 after 14:50 LST. The dominant peak of the averaged reflectivity difference occurred from 15:00 LST and would be caused by the decreased sample number for the comparison of reflectivity observed from both radars. Figure 9 shows the same information for 8 September 2012. The average reflectivity difference over the entire time period was $-2.56 \mathrm{~dB}$, and the largest difference was $-6.77 \mathrm{~dB}$. The number of samples was less than 50 until 03:10 LST, after which it increased to more than 50. This result suggests that the rainfall observed from both BSL and PSN radar was 


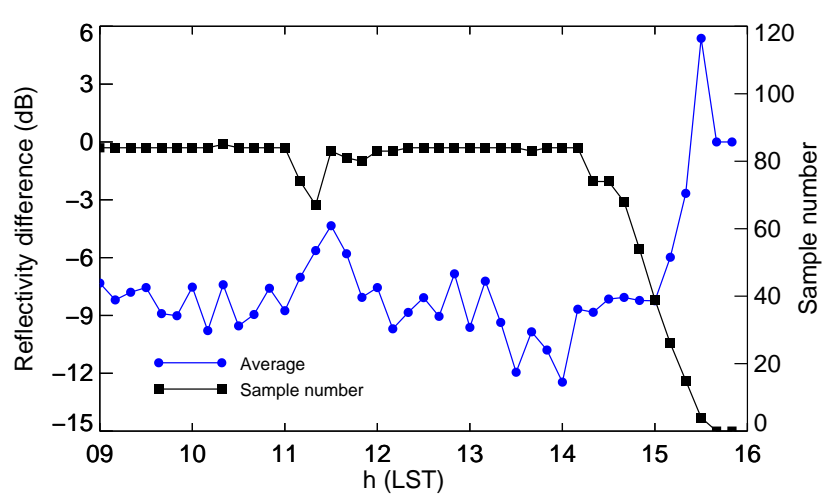

Figure 8. Time series of the average reflectivity difference between PSN and BSL at the equidistance line (blue circles) and the number of samples used in each calculation (black squares) on 25 August 2014.

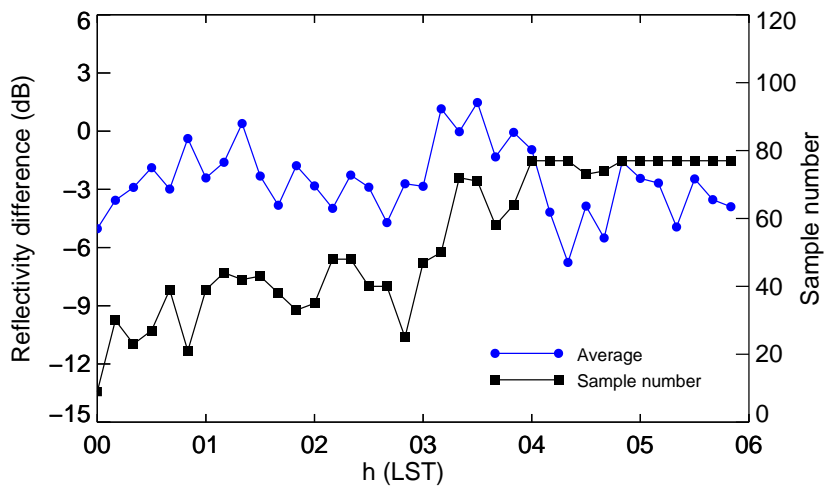

Figure 9. As for Fig. 8 but for 8 September 2012.

not located enough over the equidistance line to get a reliable comparison until 03:10 LST.

Figure 10 shows the scatter plot of total accumulated radar rainfall amount for the analyzed time period, calculated using $Z=200 R^{1.6}$ and $Z=300 R^{1.4}$, and gage rainfall, for 25 August 2014 and 8 September 2012. The RMSE, NE, and CC of rainfall pairs for $Z=200 R^{1.6}\left(Z=300 R^{1.4}\right)$ on $25 \mathrm{Au}$ gust 2014 were improved from 65.7 (66.1) to $32.6(27.0) \mathrm{mm}$, from $0.79(0.81)$ to $0.36(0.31)$, and from $0.88(0.87)$ to 0.89 (0.88), respectively. On 8 September 2012, the RMSE, NE, and CC for $Z=200 R^{1.6}\left(Z=300 R^{1.4}\right)$ changed from 30.0 (28.5) to 22.5 (20.0) $\mathrm{mm}$, from 0.58 (0.56) to 0.41 (0.36), and from $0.81(0.8)$ to $0.78(0.76)$, respectively, by the use of bias correction. In both cases, the use of corrected reflectivity for rainfall estimation resulted in much better accuracy than using raw reflectivity did.

\subsection{Overlapping area method}

Figure 11 shows time series of the mean reflectivity differences between PSN and BSL in the overlapping area and the number of samples used for calculation of $Z_{\mathrm{H}}$ bias on $25 \mathrm{Au}-$ (a)

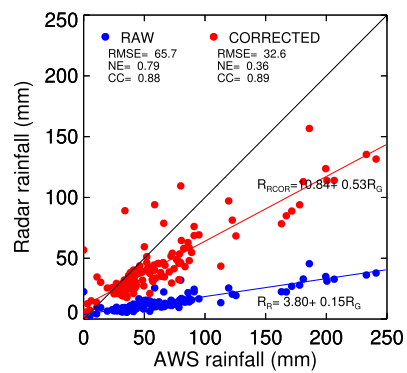

(b)

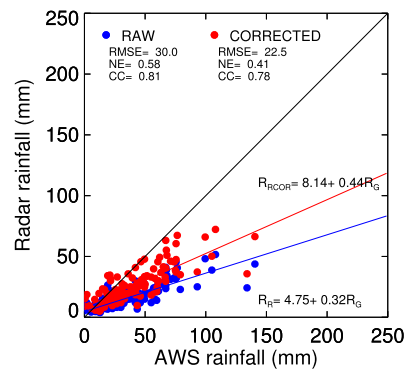

(c)

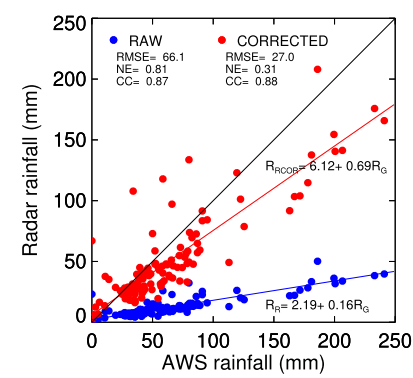

(d)

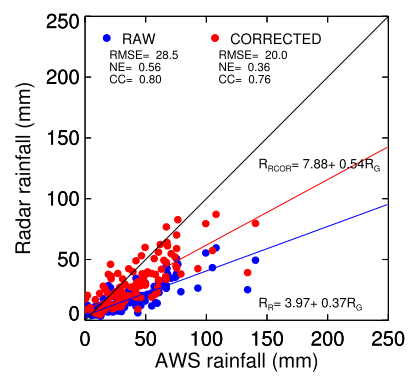

Figure 10. Scatter plot of total accumulated rainfall for analyzed time period calculated by gage and radar using (a and b) $Z=200 R^{1.6}$ and (c and d) $Z=300 R^{1.4}$ for 25 August 2014 and 8 September 2012, respectively. Blue circles show the rainfall pairs obtained using raw reflectivity and red circles show those obtained using reflectivity corrected with the equidistance line method.

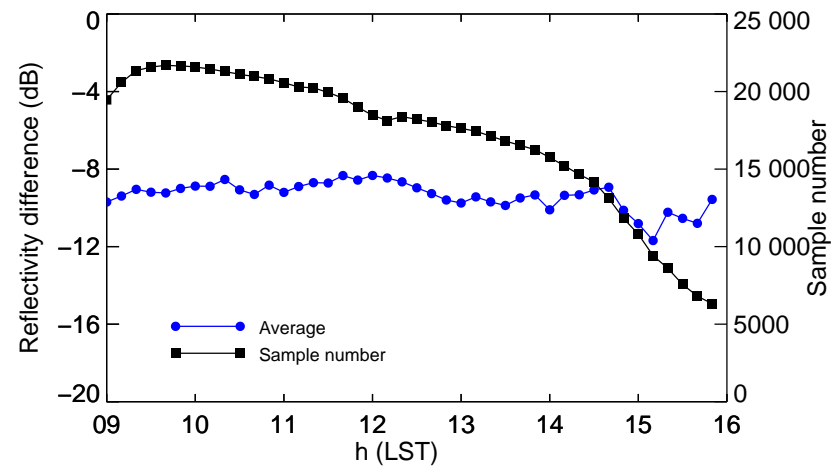

Figure 11. Time series of the average reflectivity difference between PSN and BSL at the overlapping area (blue circles) and the number of samples used in each calculation (black squares) on 25 August 2014.

gust 2014. Bias values ranged from -11.7 to $-8.3 \mathrm{~dB}$ over the period analyzed. The bias was stable until 14:40 LST, after which it fluctuated as the number of samples decreased. Figure 12 shows the same information for 8 September 2012. Bias values ranged from -4.66 to $0.22 \mathrm{~dB}$, and lower bias values occurred from 03:00 to 04:00 LST. The fluctuation also would be caused by the sudden change of microphysical characteristics of rainfall pass through the overlapping area for both radars. It would reduce the accuracy of $Z_{\mathrm{H}}$ of BSL 


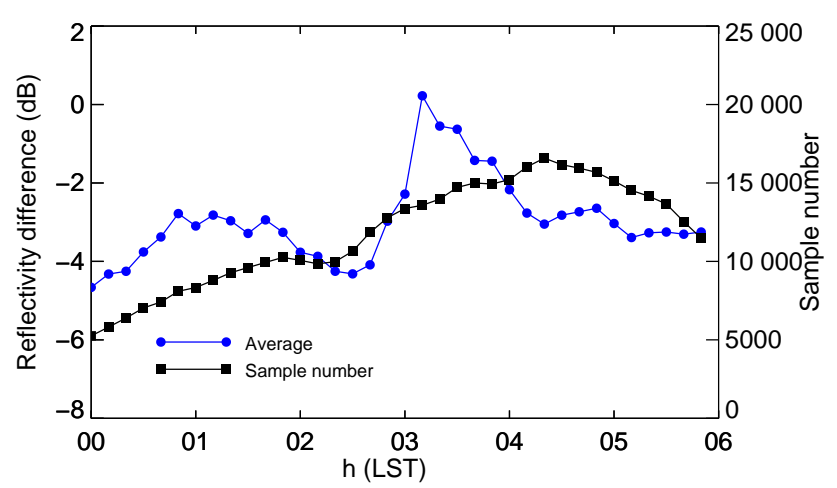

Figure 12. Time series of the average reflectivity difference between PSN and BSL at the overlapping area (blue circles) and the number of samples used in each calculation (black squares) on 8 September 2012. (a)

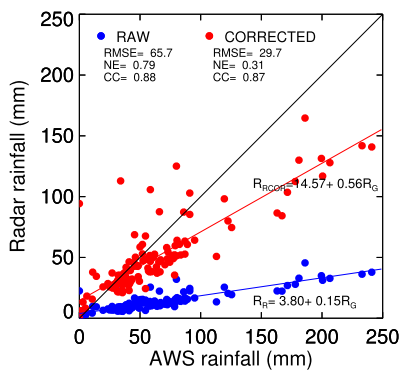

(c)

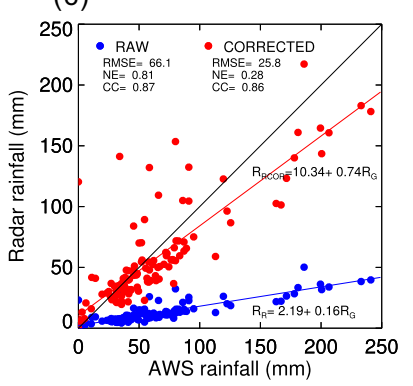

(b)

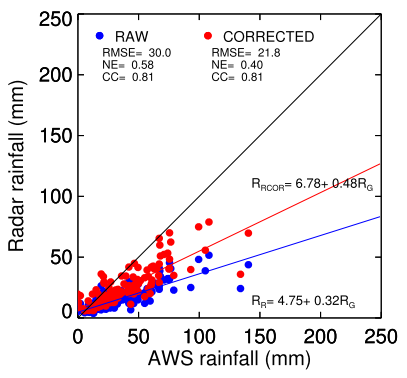

(d)

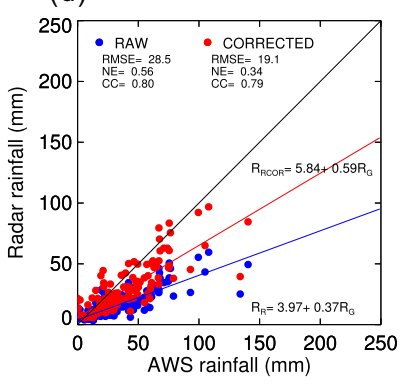

Figure 13. As for Fig. 10 but for the overlapping area method.

corrected by self-consistency. The radar rainfall estimation was done by using observed and corrected $Z_{\mathrm{H}}$ as an input of $Z-R$ relations.

Figure 13 shows a scatter plot of total accumulated radar rainfall amount for the entire analyzed time period, calculated using $Z=200 R^{1.6}$ and $Z=300 R^{1.4}$, and gage rainfall, for 25 August 2014 and 8 September 2012. The RMSE and NE of rainfall pairs for $Z=200 R^{1.6}\left(Z=300 R^{1.4}\right)$ on 25 August 2014 were improved from 65.7 (66.1) to 29.7 (25.8) $\mathrm{mm}$ and from $0.79(0.81)$ to $0.31(0.28)$, respectively. On 8 September 2012, RMSE and NE for $Z=200 R^{1.6}$ $\left(Z=300 R^{1.4}\right)$ were improved from $30.0(28.5)$ to 21.8 $(19.1) \mathrm{mm}$ and from $0.58(0.56)$ to $0.40(0.34)$, respectively,

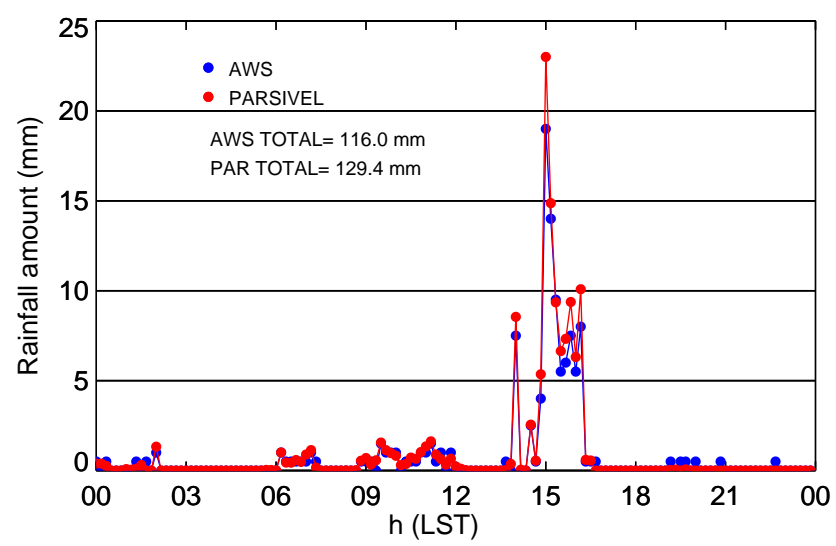

Figure 14. Time series of $10 \mathrm{~min}$ rainfall amount as obtained by PARSIVEL (red circles) and collocated gages (blue circles).

by the use of bias correction, while $\mathrm{CC}$ for $Z=200 R^{1.6}$ was unchanged at 0.81 and that of $Z=300 R^{1.4}$ changed from 0.8 to 0.79 . Again, in both cases the use of corrected reflectivity for rainfall estimation was found to improve the accuracy compared with raw reflectivity.

\subsection{Disdrometer method}

Before using the disdrometer bias correction method to estimate rainfall rates, 10 min rain rates obtained directly from DSDs and from collocated gages were compared. Figure 14 shows the time series of rain rate obtained by PARSIVEL and collocated gages on 25 August 2014. Daily total rainfall amounts for PARSIVEL and the gages were 129.4 and $116.0 \mathrm{~mm}$, respectively. The difference in the totals is only $13.4 \mathrm{~mm}$, and the RMSE and CC between the $10 \mathrm{~min}$ time series were $0.52 \mathrm{~mm} \mathrm{~h}^{-1}$ and 0.99 , respectively. On 8 September 2012 (not shown), daily total rainfall amounts for PARSIVEL and the gage were 54.4 and $55.0 \mathrm{~mm}$, respectively. The difference between the total daily rainfall amounts was $0.7 \mathrm{~mm}$ and the RMSE and CC between the two $10 \mathrm{~min}$ series were $0.62 \mathrm{~mm} \mathrm{~h}^{-1}$ and 0.96 , respectively. It is concluded that DSDs were sufficiently reliable to use as a reference with which to calculate the radar bias.

Figure 15 shows time series of reflectivity obtained by radar and by PARSIVEL, and the radar bias, on 25 August 2014. The bias was more stable before 12:00 LST than after 15:00 LST. PARSIVEL reflectivity fell to 0 from 12:30 to 13:40 LST because the precipitation system moved away from the PARSIVEL site. The sudden change of rainfall would cause the unstable reflectivity difference from 13:40 to 15:00 LST. The threshold of reflectivity value observed from both PSN and PARSIVEL should be considered for the comparison to get more reliable $Z_{\mathrm{H}}$ bias. The bias would be obtained more accurately when the reflectivity values observed from both instruments were higher than $15 \mathrm{dBZ}$ in this event. Because of this discontinuity, the bias can be considered re- 


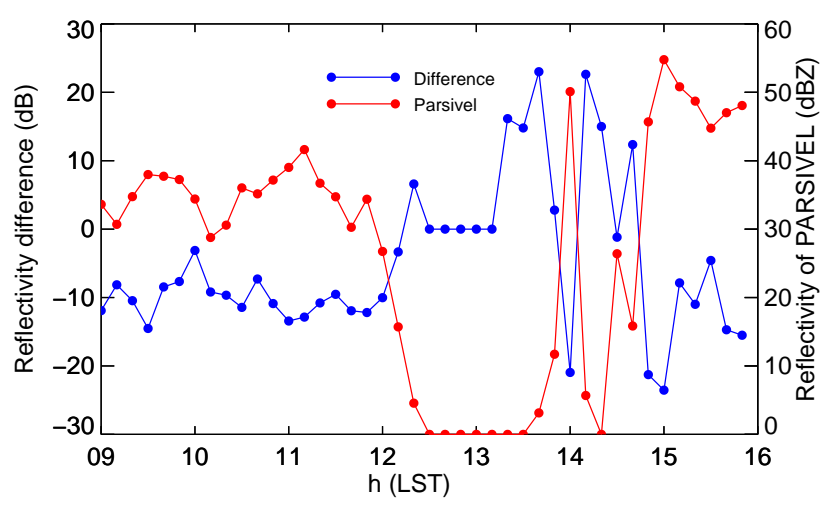

Figure 15. Time series of reflectivity obtained by PARSIVEL (red circles), and the radar bias (blue circles) on 25 August 2014.

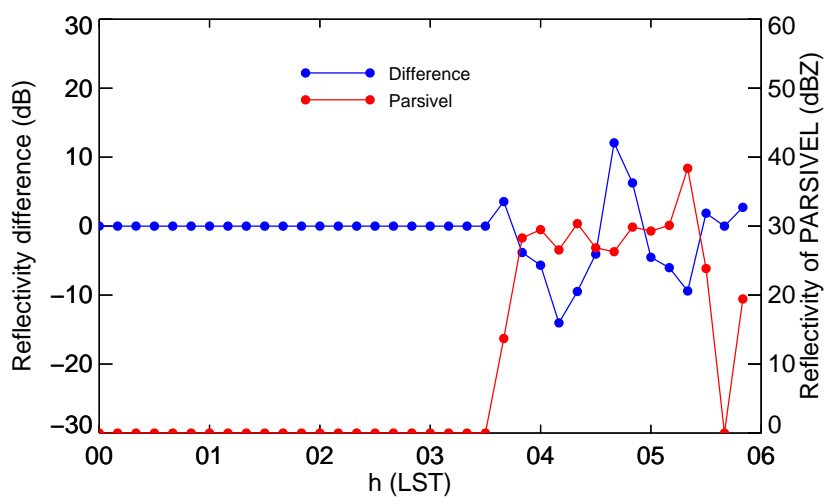

Figure 16. As for Fig. 15 but for 8 September 2012.

liable only until 12:00 LST. The bias values ranged from -13.4 to $-3.1 \mathrm{~dB}$ until 12:00 LST. Figure 16 shows time series of reflectivity obtained by radar and by PARSIVEL and the radar bias on 8 September 2012. On this occasion there were no reflectivity data from either PARSIVEL or radar until 03:30 LST. The bias values were distributed from -14.3 to $12.7 \mathrm{~dB}$.

Figure 17 shows a scatter plot of total accumulated radar rainfall amount for the entire time period, calculated using $Z=200 R^{1.6}$ and $Z=300 R^{1.4}$, and gage rainfall on 25 August 2014 and 8 September 2012. The RMSE and NE of rainfall pairs for $Z=200 R^{1.6}\left(Z=300 R^{1.4}\right)$ on 25 August 2014 were improved from $65.7(66.1) \mathrm{mm}$ to $42.0(61.4) \mathrm{mm}$ and from $0.79(0.81)$ to $0.40(0.53)$, respectively. On 8 September 2012, RMSE and NE for $Z=200 R^{1.6}\left(Z=300 R^{1.4}\right)$ decreased from 30.1 (28.6) to $24.6(23.9) \mathrm{mm}$, and from $0.58(0.56)$ to $0.46(0.44)$, respectively, while CC for $Z=200 R^{1.6}\left(Z=300 R^{1.4}\right)$ decreased from $0.81(0.8)$ to $0.65(0.59)$. In both cases, using corrected rather than raw reflectivity for rainfall estimation improved accuracy as measured by RMSE and NE but reduced accuracy as measured by $\mathrm{CC}$.
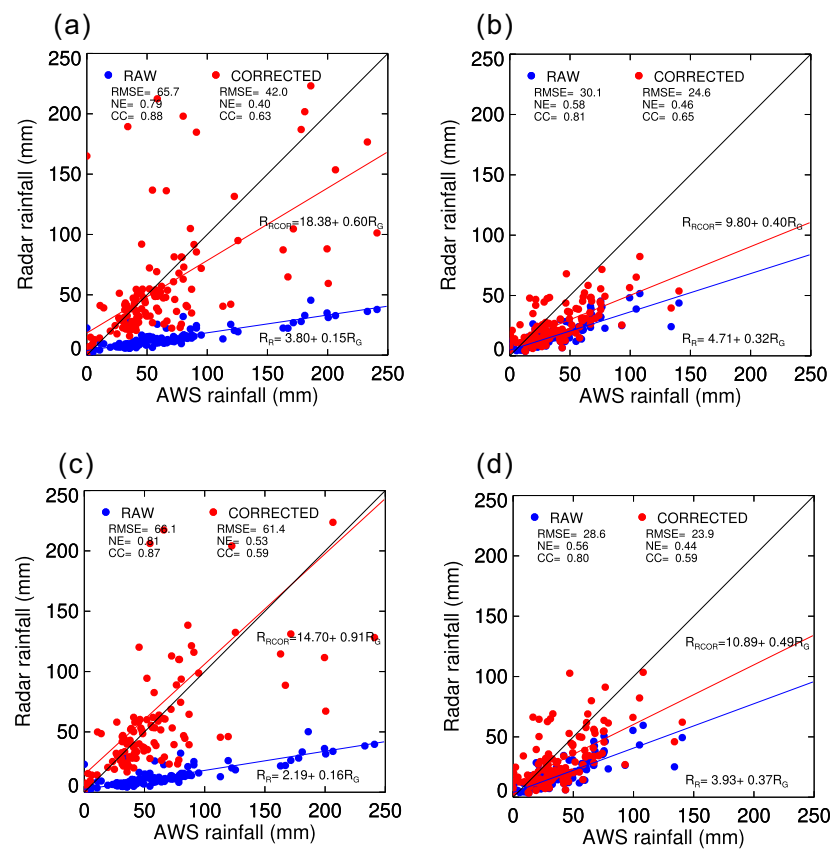

Figure 17. As for Fig. 10 but for the disdrometer method.

\subsection{Discussion}

Figure 18 shows RMSE of total rainfall amount for entire time period obtained by gage and $Z=200 R^{1.6}$ from each of the different bias correction methods on $25 \mathrm{Au}$ gust 2014 and 8 September 2012. Red, black, green, and blue bars show the RMSE obtained using the uncorrected, equidistance line, overlapping area, and disdrometer methods, respectively. The disdrometer method produced the lowest RMSE before 12:00 LST and the highest RMSE after 12:00 LST (Fig. 18a). This behavior can be attributed to the varying stability of the reflectivity calculated by PARSIVEL (Fig. 15). The overlapping method is more accurate than the equidistance line method for the entire time period, except at 14:00 LST. All the bias correction methods performed better than the uncorrected method, except for the period during which DSDs were unavailable. On 8 September 2012, the RMSE of the overlapping area method was lower than that of the other methods for the entire period, except at 05:00 and 06:00 LST (Fig. 18b). The disdrometer method produced lower RMSE at 06:00 LST, when DSDs were available, and the equidistance line method was more accurate at 05:00 LST, when the sample number was high (Fig. 15). Comparing the RMSE between two events, the large fluctuation was occurred. It would be caused by the difference of total rainfall amount between two rainfall systems. The maximum total rainfall amount for both cases were around $250 \mathrm{~mm}$ for 25 August and $150 \mathrm{~mm}$ for 8 September 2012. Another reason of the fluctuation would be the difference of radar hardware calibration error for PSN between two events. 
(a)

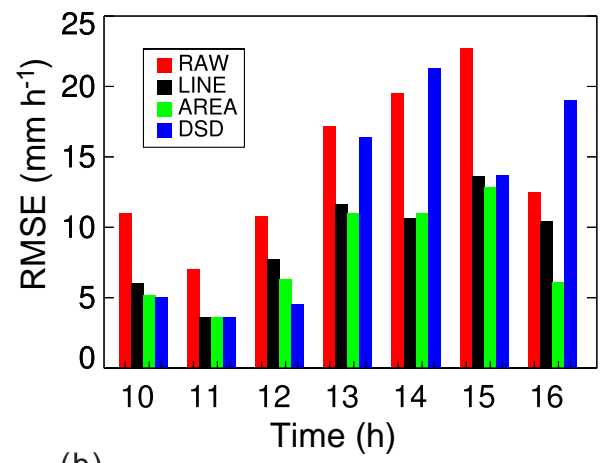

(b)

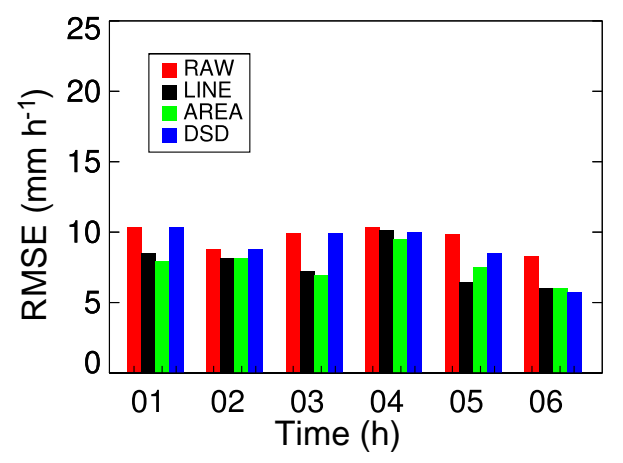

Figure 18. Accumulated rainfall RMSE calculated from radar and gage for different bias correction methods on (a) 25 August 2014 and (b) 8 September 2012. The bars with different colors show results obtained using the raw data (RAW), equidistance line method (LINE), overlapping area method (AREA), and disdrometer method (DSD).

Considering the entire period covering both events, the overlapping area method showed the best performance, as measured by RMSE. The accuracy of radar rainfall estimates could be improved by combining the three approaches, using metrics such as DSD temporal stability and the number of samples available for the equidistance line method to select the best method for a particular situation. It is worth noting that the result would be changed when the drop size distributions was fluctuated with height, especially at the layer between radar beam and ground in the disdrometer method.

\subsection{Conclusions}

Three methods for determining the reflectivity bias of single polarization radar using dual polarization radar reflectivity and disdrometer data were proposed and examined for two rainfall events caused by low pressure over the Korean Peninsula on 25 August 2014 and 8 September 2012. Single polarization radar reflectivity was underestimated by more than 12 and $7 \mathrm{~dB}$ during the August and September events, respectively. All three methods improved the accuracy of estimated rainfall, except during a period when DSDs were not observed (as the precipitation system did not pass over the disdrometer location).

The rainfall estimation using $Z=200 R^{1.6}$ and $Z=300 R^{1.4}$ and gage rainfall were examined for 25 August 2014 and 8 September 2012 to investigate the accuracy of each method. The RMSE, NE, and CC of rainfall pairs for $Z=200 R^{1.6}\left(Z=300 R^{1.4}\right)$ on 25 August 2014 with the equidistance method were improved from $65.7(66.1)$ to $32.6(27.0) \mathrm{mm}$, from $0.79(0.81)$ to 0.36 $(0.31)$, and from $0.88(0.87)$ to $0.89(0.88)$, respectively. On 8 September 2012, the RMSE, NE, and CC for $Z=200 R^{1.6}$ $\left(Z=300 R^{1.4}\right)$ changed from $30.0(28.5)$ to $22.5(20.0) \mathrm{mm}$, from $0.58(0.56)$ to $0.41(0.36)$, and from $0.81(0.8)$ to 0.78 (0.76), respectively.

The RMSE and NE of rainfall pairs for $Z=200 R^{1.6}$ $\left(Z=300 R^{1.4}\right)$ on 25 August 2014 with the overlapping method were improved from 65.7 (66.1) to 29.7 (25.8) $\mathrm{mm}$ and from $0.79(0.81)$ to $0.31(0.28)$, respectively. On 8 September 2012, RMSE and NE for $Z=200 R^{1.6}$ $\left(Z=300 R^{1.4}\right)$ were improved from $30.0(28.5)$ to 21.8 $(19.1) \mathrm{mm}$ and from $0.58(0.56)$ to $0.40(0.34)$, respectively, by the use of bias correction, while $\mathrm{CC}$ for $Z=200 R^{1.6}$ was unchanged at 0.81 and that of $Z=300 R^{1.4}$ changed from 0.8 to 0.79 .

The RMSE and NE of rainfall pairs for $Z=200 R^{1.6}$ $\left(Z=300 R^{1.4}\right)$ on 25 August 2014 with the disdrometer method were improved from $65.7(66.1) \mathrm{mm}$ to 42.0 $(61.4) \mathrm{mm}$ and from $0.79(0.81)$ to $0.40(0.53)$, respectively. On 8 September 2012, RMSE and NE for $Z=200 R^{1.6}\left(Z=300 R^{1.4}\right)$ decreased from 30.1 (28.6) to $24.6(23.9) \mathrm{mm}$, and from $0.58(0.56)$ to $0.46(0.44)$, respectively, while CC for $Z=200 R^{1.6}\left(Z=300 R^{1.4}\right)$ decreased from $0.81(0.8)$ to $0.65(0.59)$.

The use of these bias correction methods reduced rainfall RMSE by up to $50 \%$. Overall, the accuracy of rainfall estimation was highest when the overlapping area method was used to correct radar reflectivity.

The reflectivity biases obtained using the disdrometer and equidistance line methods were more temporally variable than those obtained using the overlapping area method. There were several hours during which the disdrometer method was more accurate than the overlapping area method. We suggest that combining the overlapping area method with the disdrometer method, using threshold criteria such as the temporal stability of reflectivity and the number of samples available would allow more accurate estimates of rainfall. However, optimum values for the domain size for the overlapping area method, the sample number threshold for the equidistance line method, and the reflectivity threshold for the disdrometer method should be determined in order to combine the three methods most effectively. 
Acknowledgements. The authors thank the Ministry of Land, Infrastructure, and Transport of the Korean government and the Korean Meteorological Administration for providing radar data and AWS (Automatic Weather System) gage data. This research was funded by the Korea Meteorological Industry Promotion Agency under grant KMIPA 2015-1050. This research was also partly funded by the Korea Meteorological Industry Promotion Agency under grant KMIPA 2015-5060.

Edited by: S. J. Munchak

\section{References}

Austin, P. M.: Relation between measure radar reflectivity and surface rainfall, Mon. Weather Rev., 115, 1053-1070, 1987.

Battan, L. J.: Radar Observations of the Atmosphere, The University of Chicago Press, Chicago, USA and London, UK, 324 pp., 1973.

Campos, E. and Zawadzki, I.: "Instrumental uncertainties in Z-R relations", J. Appl. Meteorol., 36, 1088-1102, 2000.

Gorgucci E., Scarchilli G., and Chandrasekar V.: Calibration of radars using polarimetric techniques, IEEE T. Geosci. Remote, 30, 853-858, 1992.

Gorgucci, E., Scarchilli, G., and Chandrasekar, V.: A procedure to calibrate multiparameter weather radar using properties of the rain medium, IEEE T. Geosci. Remote, 37, 269-276, 1999.

Goddard, J., Tan, J., and Thurai, M.: Technique for calibration of meteorological radars using differential phase, Electronic Letters, 30, 166-167, 1994.

Jang, M., Lee, D., and You, C.: Z-R relationship and DSD analyses using a POSS disdrometer. Part I: Precipitation cases in Busan, J. Korean Meteor. Soc., 40, 557-570, 2004.

Loffler-Mang, M. and Joss, J.: An optical disdrometer for measuring size and velocity of hydrometeors, J. Atmos. Ocean. Tech., 17, 130-139, 2000.

Marks, D. A., Wolff, D. B., Carey, L. D., and Tokay, A.: Quality control and calibration of the dual-polarization radar at Kwajalein, RMI, J. Atmos. Ocean. Tech., 28, 181-196, 2011.
Rinehart, R. E.: Radar for meteorologists, fifth edition, Rinehart Publications, Nevada, USA, 482 pp., 2010.

Ryzhkov, A. V., Giangrande, S. E., Melnikov, V. M., and Schuur, T. J.: Calibration issues of dual-polarization radar measurements, J. Atmos. Ocean. Tech., 22, 1138-1155, 2005.

Scarchilli, G., Gorgucci, E., Chandrasekar, V., and Dobaie, A.: Selfconsistency of polarization diversity measurement of rainfall, IEEE T. Geosci. Remote, 34, 22-26, 1996.

Trabal, J. M., Chandrasekar, V., Gorgucci, E., and McLaughlin, D. J.: Differential reflectivity (ZDR) calibration for CASA radar network using properties of the observed medium, Geoscience and Remote Sensing Symposium 2009, IEEE International, IGARSS 2009, 2, II-960-II963, 2009.

Vivekanandan, J., Zrnic, D. S., Ellis, S. M., Oye, R., Ryzhkov, A. V., and Straka, J.: Cloud microphysics retrieval using S-band dual-polarization radar measurements, B. Am. Meteorol. Soc., 80, 381-388, 1999.

Wilson, J. W. and Brandes, E. A.: Radar measurement of rainfall-A summary, B. Am. Meteorol. Soc., 60, 1048-1058, 1979.

You, C., Lee, D., Jang, M., Seo, K., Kim, K., and Kim, B.: The characteristics of rain drop size distributions using a POSS in Busan area, J. Korean Meteor. Soc., 40, 713-724, 2004.

You, C., Lee, D., Jang, M., Uyeda, H., Shinoda, T., and Kobayashi, F.: Characteristics of rainfall systems accompanied with Changma front at Chujado in Korea, Asia-Pac. J. Atmos. Sci., 46, 41-51, 2010.

You, C.-H. and Lee, D.-I.: Decadal variation in raindrop size distributions in Busan, Korea, Advances in Meteorology, 2015, 329327, 8 pp., doi:10.1155/2015/329327, 2015.

You, C.-H., Lee, D.-I., and Kang, M.-Y.: Rainfall estimation using specific differential phase for the first operational polarimetric radar in Korea, Advances in Meteorology, 2014, 41317, 10 pp., doi:10.1155/2014/413717, 2014.

Zhang, J., Wang S., and Clarke B.: WSR-88D reflectivity quality control using horizontal and vertical reflectivity structure. Preprints, 11th Conf. on Aviation, Range and Aerospace Meteorology, Hyannis, MA, USA, 5 October 2004,, Amer. Meteor. Soc., CD-ROM, P5.4, 2004 